\title{
LITERATURA FANTÁSTICA E IDENTIDAD JUVENIL. EL MAL Y LA MUERTE COMO MOTIVOS DE BÚSQUEDA DEL ADOLESCENTE
}

\author{
Isabel Jerez Martínez \\ Universidad de Castilla-La Mancha \\ Amando López Valero \\ Universidad de Murcia
}

\begin{abstract}
RESUMEN: El adolescente suele tener como motivos de búsqueda problemas asociados a la muerte, a la transgresión o a aspectos sexuales. La lectura es sin duda un medio de aproximación a estos temas y mediante la misma la persona adolescente puede hallar respuestas a las inquietudes que en esa etapa de la vida van surgiendo.

En este texto nos aproximaremos a la idea del mal y a la idea de la muerte usando principalmente dos textos de Literatura juvenil, más concretamente, relacionados con la Literatura fantástica. Así, el texto de Ursula Le Guin, Un mago de Terramar, nos permitirá apreciar desde un punto de vista antropológico cuáles son los procesos de evolución del joven ya que, Ged de Cont, debe transitar por numerosas pruebas y conocimientos que coinciden con preocupaciones de la juventud. Por otra parte, también propondremos el texto de Otfried Preussler, Krabat y el molino del diablo, donde la presencia de lo occidentalmente considerado como diabólico es una constante. El crecimiento del protagonista sirve como referencia para la reflexión de los lectores.
\end{abstract}

PALABRAS CLAVE: Literatura fantástica, tópicos literarios, Literatura juvenil, desarrollo.

\section{FANTASTIC LITERATURE AND YOUNG ADULT IDENTITY: EVIL AND DEATH AS MOTIFS FOR THE YOUNG MAN'S QUEST}

\footnotetext{
ABSTRACT: Young adult people use to have as quest-motifs problems related to death, transgression, or sexual issues. Reading is, without any doubt, a good way to approach these topics and through it teenagers can find the answers to the different questions that they have at this stage of life.
} 
In this contribution, we deal with the concept of evil, as well as with the concept of death using two texts which belong to Young adult literature. The text written by Ursula Le Guin, A Wizard of Earth Sea, will allow us to see from an anthropological point of view, a development process, because Ged de Gont, must go through different proves that take place at this stage of life. On the other hand, we will study Otfried Preussler's text, Krabat. The satanic mill, in which the topic of diabolism is constant, will well reviewed. The growing up of the main character will help us to reflect on the situation.

KEYWORDS: Fantastic literature, literary topics, Young adult literature, development.

Recibido: 24/09/2012

Aceptado: 05/11/2012

\section{LITERATURA JUVENIL: LA MAGIA DE LA NARRACIÓN}

Para muchos lectores la magia de la narración si nos referimos a lo fantástico puede residir en el cumplimiento de tareas de recuperación, evasión y consuelo que el texto les puede ofrecer. En muchas ocasiones en la base del relato fantástico se encuentra el mito o incluso el cuento de hadas. Éstos probablemente sean el acontecimiento cultural y social más importante en la vida de niños y adolescentes. Su carácter universal y belleza hacen que permanezcan en la historia sin que el paso del tiempo los erradique.

De acuerdo con Tolkien, una buena historia debe corresponderse con los siguientes parámetros: - recuperación del aprecio por las cosas sencillas que residen en nuestro mundo; - la evasión de una visión reducida de la realidad; - y el consuelo que conducirá a la persona a poder superar la sensación de miedo o mal que encuentra en el mundo real.

Todorov (1982) diferencia entre mito y leyenda al considerar que en el primero el héroe sólo tiene superioridad sobre el lector mientras que en la leyenda el héroe posee superioridad sobre el lector y las leyes de la naturaleza. En la literatura fantástica pueden acontecer ambas circunstancias. Obras magnas como El Señor de los Anillos contemplan las mismas ya que contienen las dos. Es difícil disociar la presencia del mito y la leyenda en el texto del autor galés, ya que ambos se entremezclan.

Lo maravilloso fascina a un tipo de lector que en su mayoría se corresponde con una edad adolescente y juvenil. La edad específica de estas personas supone que surjan preguntas novedosas que tienen que ver con la Religión, con la cultura, con las normas, en general, con la vida. La búsqueda de respuesta es clave en esta etapa y lo no racional implica libertad para la persona lectora, observar que en otros mundos acciones determinadas son posibles motiva que los textos de Literatura Fantástica sean atractivos para el lector. Así pues, en esta aportación, abordaremos dos de los elementos que implican preguntas trascendentes para los jóvenes: la idea del mal supone una aproximación a la transgresión y al conocimiento de lo que está prohibido y que se considera como nocivo; por otra parte, la muerte supone un desafío 
para el adolescente o joven, ya que superada la etapa infantil donde la tendencia tiene que ver con edulcorar los textos, en las obras juveniles sí que se puede hacer explícita la muerte y cómo afrontan los personajes la misma.

\section{Literatura fantástica. BreVe AProximación}

En el término Literatura fantástica confluye la participación de los fenómenos extraordinarios, mágicos o criaturas no reales. Lo irracional es un punto fundamental de esta narración. La atribución de explicación que se aleja de lo normativo imbuye al lector en un mundo distinto que le otorga una libertad deseada dentro del sistema social normativo en el cual habita. El éxito de autores como Lovecraft, Tolkien, C.S. Lewis, Ursula Le Guin o Terry Pratchett ha motivado que la Literatura fantástica haya emergido como cuestión relevante en el Siglo XX, heredando el siglo XXI el interés por este tipo de textos.

La Literatura juvenil en forma de relatos o de novelas posee una serie de características definitorias que la distinguen de otras categorías textuales. Los parámetros quedan delimitados por la imaginación y habilidad del autor de la obra. Los temas suelen estar centrados en los desafíos de la juventud, siendo en ocasiones los problemas de la persona joven el tema principal del texto. Si nos referimos a la fantasía, debemos tratar el género como el intento de resolución del conflicto establecido entre el bien y el mal. Si la obra de literatura fantástica es convincente, incidirá en la persona lectora de dos maneras: primero con la consistencia interna del nuevo mundo presentado y segundo mediante, las creencias o experiencias del protagonista. Este tipo de literatura crea un mundo paralelo que en muchas ocasiones es inventado. La dimensión épica suele estar presente en los mismos y se tratan temas sobrenaturales o relacionados con las fuerzas del mal. Algunas cuestiones recurrentes tienen que ver con la presencia de elfos, enanos, magos, hechiceros, lenguas inventadas o búsquedas.

Los mundos de la Literatura Fantástica están más o menos basados en el mundo real o en leyendas como puede ser el ejemplo del ciclo artúrico. Cuando la semejanza es clara, particularmente cuando se usa una historia del mundo real tiende hacia una historia alternativa, mientras que si la temática se centra en la lucha personal del protagonista contra las fuerzas del mal, la fantasía tiende hacia cuestiones de brujería. Algunas características claras que hay que reseñar son: - un público determinado de adultos o adolescentes; - un mundo nuevo (o continente, o al menos un país); - nuevas culturas, a veces con nuevas lenguas y religiones; tecnología medieval, a veces incluyendo estructuras sociales que tienen que ver con lo feudal; - la magia, usualmente practicada por los magos; - razas no humanas como elfos o enanos; - monstruos como troles y criaturas míticas como unicornios; - dioses que se inmiscuyen en las cuestiones humanas; y, por supuesto, batallas épicas entre el bien y el mal.

El escritor de Literatura fantástica crea un mundo distinto para los personajes y los lectores, haciendo que estos últimos crean que este nuevo mundo existe dentro del contexto que supone el libro. La aceptación de dicho mundo implica la habilidad del escritor para crear un universo imaginario que sea creíble. 


\section{INQUIETUDES DEL ADOLESCENTE: IDENTIFICACIÓN CON PERSONAJES}

En este apartado mostraremos y comentaremos algunos fragmentos de conocidas obras de la Literatura. En ellos comprobaremos la presencia del mal o de la muerte como cuestiones trascendentes que serán percibidas por las personas lectoras.

En primer lugar citaremos un fragmento de la obra El principito:

Eres un animal raro -le dijo al fin-. Delgado como un dedo...

- Pero soy más poderoso que el dedo de un rey- dijo la serpiente.

El principito sonrió:

- No eres muy poderoso..., ni siquiera tienes patas.... ni siquiera puedes viajar....

- Puedo llevarte más lejos que un navío -dijo la serpiente.

Saint Exupéry (1999: 60).

Observamos en el mismo la presencia de la serpiente como elemento tentador, inspirado en los referentes religiosos. El mal sería el elemento evidente que se muestra en el fragmento. Dicha tentación, finalmente desemboca en un desenlace que tiene que ver con la muerte, algunos estudiosos también lo relacionan con el suicidio:

No hubo nada más que un relámpago amarillo cerca de su tobillo. Quedó inmóvil un instante. No gritó. Cayó suavemente, como cae un árbol. En la arena, ni siquiera hizo ruido.

Saint Exupéry (1999: 91).

La tentación en forma de mal también es hallada en otros textos clásicos de lo fantástico. Citamos a continuación un pasaje de Las crónicas de Narnia, concretamente del libro: El león, la bruja y el armario:

- Mi pobre criatura -dijo en un tono de voz bastante distinto-, ipareces congelado! Ven y siéntate conmigo aquí en el trineo; colocaré mi manto a tu alrededor y conversaremos.

A Edmund no le gustó nada aquel plan pero no se atrevió a desobedecer, montó en el trineo se sentó a sus pies, y ella colocó un pliegue del manto a su alrededor y lo arropó bien con él.

- ¿Tal vez algo caliente para beber? -sugirió la reina-. ¿Te gustaría?

Lewis (2005: 46).

Otro ejemplo clásico de tentación que inspira a los anteriores es el texto clásico de Sir Gawain y el caballero verde (2005: 28-29):

Si hay alguno en esta corte que se tenga por espíritu audaz, y de sangre y alma fogosa, y que se atreva a descargar un golpe a cambio de otro, le daré como presente esta hacha costosa; esta hacha, bastante pesada, para que él la utilice a su gusto. Yo esperaré el primer golpe, tan desarmado como voy aquí. Si hay algún hombre tan fiero que quiera probar lo que aquí propongo, que venga a mí sin más demora y se haga cargo de esta arma; se la entrego para siempre. Entre tanto, yo aguardaré impasible su golpe, a pie firme, en el mismo suelo, con tal que pueda yo asestarle otro sin reparo. Sin embargo, le concederé el plazo de un año y un día. ¡Así que venga pronto ahora, quienquiera que se atreva a responder! 
Esas demostraciones de tentación, derivan contemporáneamente en el mal. Así, en el texto clásico de Eddison, La serpiente Uróboros, la invocación del mal se hace explícita y se torna en atractiva para la persona lectora:

- Por estas figuras dibujadas y por estos conjuros encantados, por la unción del lobo y la salamandra, por el signo no bendito de Cáncer que ahora se inclina hacia el sol y por el corazón ardiente de Escorpio que se abrasa en esta hora en el meridiano de la noche, tú eres mi esclavo y mi instrumento. Rebájate a servirme, serpiente del pozo. De lo contrario, suscitaré de la noche antigua a inteligencias y dominios mucho más poderosos que tú, y servirán a mis fines, y a ti te encadenarán con cadenas de fuego inextinguible y te arrastrarán por lo profundo de tormento en tormento.

Entonces se calmó el terremoto y no quedó sino una vibración de las paredes y del suelo y el viento de las invisibles y el olor caliente de hollín y azufre ardiente. Y salió una voz extrañamente dulce del aire cargado de aquella cámara, y dijo:

- Miserable maldito que agitas nuestra paz, ¿cuál es tu voluntad?

Eddison (2004: 74).

Más cuestiones relacionadas con el mal las encontramos en Harry Potter el personaje más famoso de la Literatura Juvenil en la última década. Creado por Rowling ha supuesto un impacto notable entre la población lectora que se encuentra a caballo entre lo infantil y lo juvenil:

- Sería extraordinario que el mismo día en que Quien-usted-sabe parece haber desaparecido al fin, los muggles lo descubran todo sobre nosotros. Porque realmente se ha ido, ¿no, Dumbledore?

Rowling (1999: 16).

- Eso no es todo. Dicen que quiso matar al hijo de los Potter, a Harry. Pero no pudo. No pudo matar a ese niño. Nadie sabe por qué, ni cómo, pero dicen que como no pudo matarlo, el poder de Voldemort se rompió... y que ésa es la razón por la que se ha ido.

Rowling (1999: 18).

Pero sin duda si queremos ver aunadas cuestiones de tentación y de mal, tenemos que aludir al pasaje que concierne a Frodo situado en el Monte del Destino, en El Señor de los Anillos:

Entonces Frodo pareció despertar, y habló con una voz clara, una voz límpida y potente que Sam no le conocía, y que se alzó sobre el tumulto y los golpes del Monte del Destino, y retumbó en el techo y las paredes de la caverna.

- He llegado -dijo-. Pero ahora he decidido no hacer lo que he venido a hacer. No lo haré. ¡El anillo es mío! Y de pronto se lo puso en el dedo, y desapareció de la vista de Sam. Sam abrió la boca y jadeó, pero no llegó a gritar, porque en aquel instante ocurrieron muchas cosas.

Tolkien (2003: 255). 
Y explicitando las relaciones entre el mal y la muerte hallamos uno de los fragmentos clave de la historia de la Literatura fantástica. En el momento en el cual Gandalf lucha contra el Balrog se aúnan el mal y la muerte en un mismo espacio narrativo. La muerte del mago tiene que ser aceptada por la comunidad del anillo tras la lucha de Gandalf con el Balrog, símbolo del mal:

El Balrog llegó al puente. Gandalf aguardaba en el medio, apoyándose en la vara que tenía en la mano izquierda; pero en la otra relampagueaba Glamdring, fría y blanca. El enemigo se detuvo de nuevo, enfrentándolo, y la sombra que lo envolvía se abrió a los lados como dos vastas alas. En seguida esgrimió el látigo, y las colas crujieron y gimieron. Un fuego le salía de la nariz. Pero Gandalf no se movió.

- No puedes pasar -dijo. Los orcos permanecieron inmóviles, y un silencio de muerte cayó alrededor-. Soy un servidor del Fuego Secreto, que es dueño de la Ilama de Anor. No puedes pasar. El fuego oscuro no te servirá de nada, Ilama de Udûn. ¡Vuelve a la Sombra! No puedes pasar.

El Balrog no respondió. El fuego pareció extinguirse y la oscuridad creció todavía más. El Balrog avanzó lentamente, y de pronto se enderezó hasta alcanzar una gran estatura, extendiendo las alas de muro a muro; pero Gandalf era todavía visible, como un débil resplandor en las tinieblas; parecía pequeño, y completamente solo; gris e inclinado, como un árbol seco poco antes de estallar la tormenta.

De la sombra brotó llameando una espada roja.

Glamdring respondió con un resplandor blanco.

Hubo un sonido de metales que se entrechocaban y una estocada de fuego blanco. El Balrog cayó de espaldas y la hoja le saltó de la mano en pedazos fundidos. El mago vaciló en el puente, dio un paso atrás, y luego se irguió otra vez, inmóvil.

- ¡No puedes pasar! -dijo.

El Balrog dio un salto y cayó en medio del puente. El látigo restalló y silbó.

- ¡No podrá resistir solo! -gritó Aragorn de pronto y corrió de vuelta por el puente¡Elendil! -gritó-. ¡Estoy contigo, Gandalf!

- ¡Gondor! -gritó Boromir, y dando un salto fue detrás de Aragorn.

En ese momento, Gandalf alzó la vara y dando un grito golpeó el puente ante él. La vara se quebró en dos y le cayó de la mano. Una cortina enceguecedora de fuego blanco subió en el aire. El puente crujió, rompiéndose justo debajo de los pies del Balrog, y la piedra que lo sostenía se precipitó al abismo mientras el resto permanecía allí, en equilibrio, estremeciéndose como una lengua de roca que se asoma al vacío. Con un grito terrible el Balrog se precipitó hacia delante; la sombra se hundió y desapareció. Pero aun mientras caía sacudió el látigo, y las colas azotaron y envolvieron las rodillas del mago, arrastrándolo al borde del precipicio. Gandalf se tambaleó y cayó al suelo, tratando vanamente de asirse a la piedra, deslizándose al abismo.

- ¡Huid, insensatos! -gritó, y desapareció.

Tolkien (388-390).

Sin duda que este enfrentamiento y sus consecuencias muestran perfectamente la simbiosis entre el mal y la muerte y cómo influyen en los personajes de la historia. La emoción que embarga a la persona lectora al leer y comprender estas líneas supone un hito en la Literatura Fantástica e invita a la reflexión acerca de ambos conceptos. 


\section{Descubriendo el mal y la muerte: Krabat y Ged de Gont}

Uno de los referentes de la historia de la Literatura como es el personaje del doctor Fausto nos proporciona la comprensión relativa a que el bien es incomprensible sin la presencia del mal. La misteriosa batalla entre los mismos en el marco del alma humana es retratada en el mito de Fausto. La búsqueda espiritual del hombre le hace vender su alma al diablo. Su reconocimiento de lo árido y hedonista de la tierra y su redención nos ayuda a comprender la luz y la oscuridad para la búsqueda de la paz. Así, dicha temática puede ser reconocida en un texto de la Literatura fantástica como es el creado por Otfried Preussler. Basada en una historia tradicional, el joven Krabat se convertirá en aprendiz de mago de las artes oscuras. En el desarrollo argumental, la magia, la muerte, el destino y la amistad serán temas reflejados en esta historia.

Inspirándonos en una tradición occidental podemos encontrar similitudes entre el pacto que Krabat establece con el maestro y el pacto establecido entre Fausto y Mefistófeles:

El molinero le extendió la mano izquierda.

- ¡Chócala! -dijo.

En el mismo instante en que estrecharon sus manos, se oyó un sordo rumor en la casa. Parecía provenir de las profundidades. El suelo empezó a temblar, las paredes vacilaron, los postes y las vigas se estremecieron.

Krabat gritó y quiso echar a correr, lejos, muy lejos de allí..., pero el maestro se interpuso en su camino.

- ¡El molino! -exclamó colocando las manos en la forma de tolva-. ¡Ya vuelve a moler!

Preussler (2009: 13)

Al aceptar el pacto, el joven se introduce en una atmósfera en principio relacionada con el mal, adentrándose en las artes oscuras que le conducen a tener la capacidad de transformación:

Luego se acercó a Krabat y le tocó con la mano izquierda en el hombro izquierdo. A Krabat le recorrió un escalofrío; luego, sintió cómo iba encogiéndose: su cuerpo fue haciéndose más pequeño, le salieron plumas de cuervo, un pico y garras. Dando saltos en el umbral fue a posarse a los pies del maestro y no osó mirarle.

Preussler (2009: 40-41)

Señaló con un dedo a un cuervo y le ordenó repetir el texto y la fórmula mágica. - Éste es el arte de cegar una fuente, de manera que de un día para otro deje de dar agua.

Preussler (2009: 43)

Y a lo largo de la historia comprobamos los rituales que directamente se relacionan con la idea del mal:

Yo me inclino bajo el yugo de la hermandad secreta.

El maestro los esperaba en zaguán. A cada uno de ellos le daba un cachete en la mejilla derecha y le decía:

- ¡Recuerda que eres un discípulo! 
Luego le daba un cachete en la mejilla izquierda y añadía:

- ¡Recuerda que yo soy el maestro!

Después, cada muchacho tenía que inclinarse tres veces ante el molinero y alabarle:

- Te obedeceré en todas las ocas, maestro, ahora y siempre.

Preussler (2009: 54).

Y unido a ese pacto con lo oscuro se incluye en el texto la muerte de compañeros de Krabat en el molino. El contacto del adolescente protagonista de la historia con la muerte se hace explicito en el siguiente fragmento:

A la mañana siguiente, la de Año Nuevo, encontraron a Tonda, boca abajo, tendido en el suelo de la entrada. Los chicos del molino no parecieron sorprenderse. Sólo a Krabat no le cabía en la cabeza que Tonda estuviese muerto. Sollozando se echó sobre él, y le llamó por su nombre, y le suplicó:

- ¡Dime, Tonda, dime algo!

Cogió la mano del muerto. El día anterior lo había sentido vivo, cuando le puso la mano en la frente, antes de dormirse. Ahora estaba inmóvil y frío. Ahora parecía estar muy lejos, muy lejos de él.

Preussler (2009: 95).

Incluso los compañeros de Krabat, emiten palabras que sin duda hacen reflexionar al lector acerca del tema de la muerte:

Los muertos están muertos -dijo Michal-. Ya te lo he dicho y te lo volveré a decir. Quien se muere en el molino de Koselbruch tiene que ser olvidado, como si nunca hubiera existido; sólo así continuará viviendo para los demás. Prométeme que recordarás esto que te digo.

Preussler (2009: 151).

El final feliz de la historia, en el que acontece la rebelión de Krabat y la liberación de los jóvenes por parte de Cantora, supone un tipo de enseñanza que la persona lectora puede adquirir:

Krabat recordaba la conversación que tuvo con Tonda hacía un año, poco más o menos, por esa época. ¿Estaban ahora los chicos atemorizados porque presentían que la muerte se llevaría a uno de ellos?

Preussler (2009: 171).

¿Tú sabes -preguntó Lobosch- quién es el culpable de la muerte de Tonda y de Michal?

- Me lo supongo -dijo Krabat-. Y si mis sospechas se confirman, haré un ajuste de cuentas.

Preussler (2009: 209).

El maestro, tambaleándose, se apoyó contra la pared. Los chicos permanecían en su sitio, como petrificados.

Preussler (2009: 269). 
Finalmente, el mensaje de la obra lo transmite la conversación entre Krabat y Cantora en el cual se ofrecen las pautas para que el comportamiento de las personas se oriente de una manera determinada:

- ¿Cómo es que pudiste reconocerme entre los compañeros?

- Sentí que tenía miedo -contestó ella-, miedo por mí, y por eso pude reconocerte.

Preussler (2009: 269)

Sentimientos, emociones y pasiones se muestran en el texto y podríamos establecer paralelismos entre Krabat y el Doctor Fausto (aunque con circunstancias distintas) y el maestro y Mefistófeles. A este último se conoce a uno de los príncipes del Infierno, subordinado a Satanás, como el que captura las almas para el infierno. En este caso el maestro trabaja para el padrino. Lo esencialmente humano va de la mano del mal como si estuvieran incluidos en la misma categoría, como si uno alimentara al otro y viceversa. Pareciera que aquellas cosas pasionales que mueven al ser humano se encuentran en el limbo entre lo bueno y lo malo, que son amorales, neutras. Digamos que el mal motiva la mayoría de ellas sin embargo al final son estas mismas acciones las que permiten que las pasiones terminen del lado del bien.

El segundo de los casos tiene que ver con el protagonista de Terramar, Ged de Gont, este proyecto de archimago (en el primero de los libros de la saga) flirtea con lo peligroso, con el mal, y presenta su relación con el mismo como algo que no atemoriza al protagonista:

- ¿Cómo se llama ese hechizo que trae el halcón?

- Es un sortilegio de llamada.

- ¿Puedes traer también a los espectros de los muertos?

Ged pensó que se burlaba de él con esa pregunta, pues el halcón no había obedecido del todo a la amada. No permitiría que se burlase de él.

Podría si quisiera -respondió con voz calma.

- ¿No es muy difícil, muy peligroso, llamar a un espectro?

- Difícil, sí lo es-. ¿Peligroso? - Ged se encogió de hombros.

Le Guin (2005: 34).

Posteriormente, una vez en la isla de Roke, se desencadena el contacto de Ged de Gont con el mal cuando reta a Jaspe en un duelo referido a la satisfacción del ego:

No tengas miedo -dijo, con una sonrisa-. Llamaré al espíritu de una mujer. No tienes por qué temer a una mujer. A Elfarrán Ilamaré, la bella dama de la Gesta de Enlade.

Le Guin (2005: 79).

Un instante apenas centelleó allí el espectro. Luego el óvalo lívido se encendió entre los brazos de Ged, creció y se extendió, una fisura en la oscuridad de la tierra y la noche, una herida abierta en la urdimbre del mundo. En ella brillaba una luz incandescente y aterradora. $Y$ por esa brecha informe y luminosa trepaba reptando una cosa semejante a un terrón de sombra negra: rápida y repugnante, se lanzó directamente a la cara de Ged.

Le Guin (2005: 80). 
Tras ser desterrado, y constituyendo un peligro para sus compañeros, Ged inicia una travesía que en realidad es una lucha contra su sombra, contra el lado oscuro que él posee. Cuando Ged decide enfrentarse a su sombra, el desenlace correspondiente es un deleite para la persona lectora:

Ged alzó entonces la vara, bien alto, y el resplandor fue de pronto intolerable, de una blancura tan ardiente que dominó y arrasó aquella antigua oscuridad. Bajo esa luz, toda forma humana se desprendió con una piel de la cosa que avanzaba hacia Ged. Se encogió y se contrajo, se ennegreció, mientras reptaba por la arena en cuatro cortas patas provistas de garras y zarpas. Mas todavía avanzaba, alzando hacia Ged un hocico ciego, informe, sin labios, sin orejas ni ojos. Y en el momento en que estuvieron frente a frente, la blanquísima luz mágica de la vara, se hizo, completamente negra y se irguió. En silencio, hombre y sombra se encontraron cara a cara y se detuvieron.

En voz alta y clara, rompiendo aquel viejo silencio, Ged pronunció el nombre de la sombra, y en el mismo instante, habló la sombra, sin labios ni lengua, y dijo la misma palabra: - Ged. - Y las dos voces fueron una sola voz.

Ged soltó la vara, extendió los brazos y abrazó a la sombra, a la negra mitad que reptaba hacia él. Luz y oscuridad se encontraron, se fusionaron, se unieron.

Le Guin (2005: 211-212).

Las siguientes palabras:

Sólo en el silencio la palabra, sólo en la oscuridad la luz, sólo en la muerte la vida; el vuelo del halcón brilla en el cielo vacío.

Le Guin (2005: 214).

nos muestran la relación que hemos establecido en este texto, la persona lectora precisa apreciar que para que el ser humano se manifieste en su plenitud necesita de contrastes, por lo que la muerte complementa a la vida y el mal lo hace con el bien. Dichos entes se muestran en la Literatura Fantástica y contribuyen a que la persona pueda intentar resolver las cuestiones que surgen en esa etapa de la vida.

\section{CONCLUSIONES}

Una vez realizado el recorrido por los distintos textos que aluden a los dos conceptos principales de esta aportación, queremos recapitular lo expuesto incidiendo en las cuestiones que consideramos fundamentales. Así, las preguntas que el adolescente o joven se plantea en una etapa concreta de la vida tienen su reflejo en los mundos fantásticos que el tipo de Literatura que estamos tratando recrea. Los dos temas usados en este texto, tanto la muerte como el mal, son motivo de curiosidad por parte de estas personas y tratan de indagar y tratar con los mismos con el fin de rebatir las indicaciones que desde el mundo adulto se les han proporcionado. Hemos comprobado en diferentes fragmentos de obras contemporáneas relevantes que ambos conceptos se hallan explícitos en las obras y en algunas de ellas actúan como hilo conductor.

Consideramos positiva la presencia de estos tópicos en la Literatura ya que deben ayudar al crecimiento personal del joven o adolescente permitiéndole refle- 
xionar sobre conceptos que van a estar presentes en su vida. Debido a la conformación social occidental la idea del mal se encuentra bien delimitada y es la persona lectora la que tiene que definir su postura ante el mismo (o reconsiderar la idea social); mientras que la muerte es inherente al ser humano, mediante la reflexión es posible modificar actitudes y afrontar situaciones que sin duda acontecerán a lo largo de la vida. Por tanto, abogamos por el uso de la Literatura fantástica y ensalzamos los temas incluidos en la misma ya que ayudan a la persona a alcanzar un desarrollo integral de su ser.

\section{REFERENCIAS BIBLIOGRÁFICAS}

EDDISON, E. R. (2004) (1926). La serpiente Uróboros. Madrid: Minotauro.

ENCABO, E. y JEREZ-MARTíNEZ, I. (2008). The influence of Richard the Lionheart on British Young Adult texts: exploring the maps. ID EST, 1, 29-36.

HERRERO, J. (2000). Estética y pragmática del relato fantástico: las estrategias narrativas y la cooperación interpretativa del lector. Cuenca: Servicio de publicaciones de la Universidad de Castilla-La Mancha.

LE GUIN, U. (2005) (1968). Un mago de Terramar. Madrid: Minotauro.

LEWIS, C. S. (2005) (1950). El león, la bruja y el armario. Barcelona: Destino.

LUKENS, R. (2007). A critical handbook of Children's Literature. Boston: Pearson.

PREUSSLER, O. (2009) (1981). Krabat y el Molino del Diablo. Barcelona: Noguer.

ROWLING, J. K. (1999) (1997). Harry Potter y la piedra filosofal. Madrid: Salamandra. SAINT EXUPÉRY, A. (1999) (1946). El principito. Buenos Aires: Emecé.

TODOROV, T. (1982). Introducción a la literatura fantástica. Barcelona: Ediciones Buenos Aires.

TOLKIEN, J. R. R. (2003) (1966). El Señor de los anillos. Madrid: Minotauro.

TORRES OLIVER, F. (Trad.) (2005). Sir Gawain y el caballero verde. Madrid: Anaya. ZIPES, J. (1983). Fairy tales and the art of subversion. The classical genre for children and the process of civilization. New York: Routledge. 
